\title{
RANCANG BANGUN JARINGAN MENGGUNAKAN MODE PPOE CLIENT MIKROTIK DAN METODE PCQ DI JARINGAN INTERNET SMA NEGERI 20 MEDAN
}

\author{
Dian Kurnia ${ }^{1}$, Suci Ramadhani ${ }^{2}$, Supiyandi ${ }^{3}$ \\ ${ }^{123}$ Universitas Pembangunan Panca Budi Medan \\ Jl. Jend. Gatot Subroto Km. 4,5 Sei Sikambing 20122 Medan \\ diankurnia68@dosen.pancabudi.ac.id ${ }^{1}$,suciramadhani@dosen.pancabudi.ac.id ${ }^{2}$, \\ supiyandi@dosen.pancabudi.ac.id ${ }^{3}$
}

\begin{abstract}
Abstrak - Penelitian ini akan menggunakan modem ADSL yang disetting bridge agar dapat memanfaatkan mikrotik sebagai PPoe client yang dapat terkoneksi langsung ke IP Public dengan username dan password yang diberikan oleh ISP pada setiap modem. Kemudian akan dilanjutkan dengan pembagian bandwidth dengan metode PCQ pada routerboard mikrotik di jaringan wifi lingkungan sekolah SMAN 20 Medan. Pada jaringan wifi tersebut akan terkoneksi beberapa user kemudian akan dimonitoring antrian queue tree yang aktif dengan batasan IP Address yang telah ditentukan pada list firewall dan pengukuran dilakukan dengan berdasarkan parameter kualitas jaringan berupa ukuran data download, delay dan loss bandwidth. Pengumpulan data akan dibantu dengan aplikasi Wireshark. Penelitian ini diharapkan dapat analisis QoS pada trafik sibuk dengan memodelkan persamaan yang cocok untuk performansi jaringan wifi di lingkungan SMAN 20 Medan pada metode management bandwitdth PCQ, sehingga dapat meningkatkan kualitas jaringan internet di SMAN 20 Medan. Apalagi dipermudah dengan trouble shooting jarak jauh..
\end{abstract}

Kata kunci - Modem ADSL, Mikrotik, PPoe Client

\section{PENDAHULUAN}

Dalam perkembangan teknologi sekarang ini, internet sangat dibutuhkan oleh kalangan pendidikan khususnya siswa-siswi di bidang IT. Untuk memenuhi kebutuhan siswa tersebut dalam menjalankan aktivitas kegiatan browsing, streaming, upload dan download dibutuhkan management bandwidth yang baik agar setiap user yang aktif tidak dirugikan. Oleh karena itu dibutuhkan metode management bandwidth dalam melimit bandwidth dan pembagian bandwidth secara merata.

(Mirsantoso, 2015), membagi bandwidth internet dengan menggunakan metode Peer Connection Queue (PCQ) pada jaringan laboratorium komputer, pengujian yang dilakukan dengan menonaktifkan rate limit pada PCQ ternyata tidak mempengaruhi limit download yang dilakukan oleh klient dengan menggunakan software internet download manager dan pengujian dilanjutkan dengan mengaktifkan rate limit pada PCQ ternyata mempengaruhi limit kecepatan download yang dilakukan oleh klient baik menggunakan software maupun tidak menggunakan software downloader.

Pada penelitian sekarang penulis menggunakan modem ADSL yang disetting bridge agar dapat memanfaatkan mikrotik sebagai PPoe client yang dapat terkonkesi langsung ke IP Public dengan username dan password yang diberikan oleh ISP pada setiap modem. Kemudian akan dilanjutkan dengan pembagian bandwidth dengan metode PCQ pada routerboard mikrotik di lingkungan sekolah
SMAN 20 Medan. Parameter kualitas jaringan yang akan diukur berupa ukuran data download, transfer rate bandwidth, throughput, delay dan loss bandwidth.

Penelitian ini diharapkan dapat analisis QoS pada trafik sibuk dengan memodelkan persamaan yang cocok untuk performansi jaringan wifi di lingkungan SMAN 20 Medan pada metode management bandwitdth PCQ, sehingga dapat meningkatkan kualitas jaringan internet di SMAN 20 Medan. Apalagi dipermudah dengan trouble shooting jarak jauh menggunakan ip public pada winbox.

\section{METODOLOGI PENELITIAN}

Sistematika perangkat penelitian diperlukan dalam membangun metode penelitian. Sehingga hasil penelitian nantinya lebih prosedural dan releven. Adapun perangkat penelitian dalam membangun metode penelitian yaitu sebegai berikut :

\section{A. Materi Penelitian}

Adapun materi penelitian dalam hal ini menyangkut :

1. Bahan penelitian

Adapun bahan yang akan digunakan adalah

a) Bandwidth

Adapun besarnya bandwidth yang digunakan adalah yang bersumber dari ISP yang digunakan SMAN 20 Medan sebesar 10 Mbps. 
b) Topologi jaringan

Adapun topologi jaringan yang digunakan adalah sebagai berikut :

Page | 29

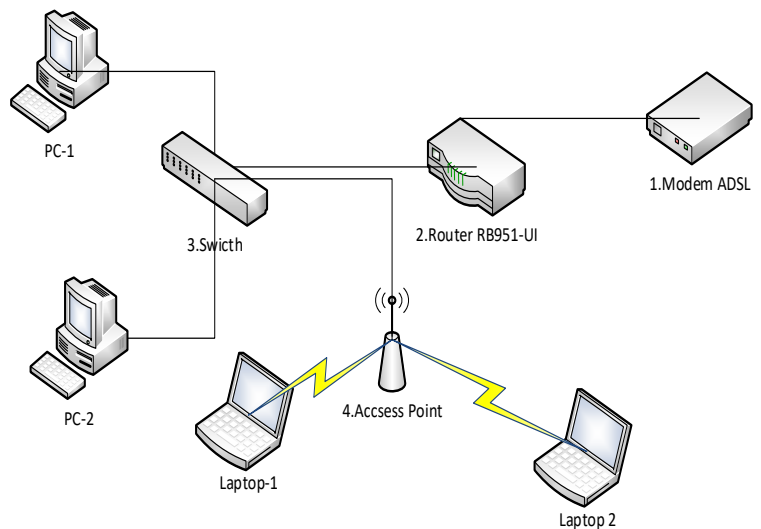

Gbr 1. Rancangan topologi jaringan yang akan diterapkan

Pada gambar rancangan topologi jaringan diatas menjelaskan bahwa topologi yang di rancang menggunakan modem ADSL dengan mode bridge dalam hal ini mengggunakan paket INDIHOMESPEEDY 10 Mbps kemudian IP Address LAN modem diteruskan ke mikrotik untuk disetting routing ke masing-masing port LAN mikrotik sesuai dengan fungsi yang telah digambarkan pada gambar 13 topologi diatas. Port 1 mikrotik disetting PPoe Client menerima IP Public dengan username dan password login yang disediakan oleh modem ADSL kemudian port 2 dan 3 mikrotik akan mengirimkan IP Address secara DHCP yang telah di setting management bandwidthnya dengan menerapkan Peer Connection Queue (PCQ) dan dihubungkan port swicth port 4 dan port 5 pada mikrotik tidak setting, untuk standby saja apabila port 1 dan 2 terjadi kerusakan.

TABEL 1

KONFIGURASI IP PADA JARINGAN YANG DIRANCANG

\begin{tabular}{|c|c|c|c|}
\hline No & $\begin{array}{c}\text { Hardware } \\
\text { Network }\end{array}$ & $\begin{array}{c}\text { Port } \\
\text { Ether } \\
\text { net }\end{array}$ & IP \\
\hline 1 & $\begin{array}{c}\text { Modem } \\
\text { ADSL }\end{array}$ & 1 & Ip Mode Bridge \\
\hline 2 & Router & 1 & Address PPoe Client \\
& & & Netmask PPoe Client \\
& & & $\begin{array}{l}\text { Address } \\
192.168 .2 .0 / 24\end{array}$ \\
\cline { 3 - 4 } & & & Netmask 255.255.255.0 \\
& & &
\end{tabular}

\begin{tabular}{|c|c|l|l|}
\hline 3 & Swicth ke & 2 & $\begin{array}{l}\text { Address } \\
\text { 192.168.2.2/24- } \\
\end{array}$ \\
& PC-Client & & 192.168.2.254/24 \\
& & & Netmask 255.255.255.0 \\
& & & Gateway 192.168.2.1 \\
\hline 4 & $\begin{array}{c}\text { Access } \\
\text { Point }\end{array}$ & 3 & Address \\
& & & Netmask 255.255.255.0 \\
& & & \\
\hline
\end{tabular}

2. Peralatan Penelitian

Adapun topologi jaringan yang akan digunakan dalam perancangan jaringan di SMP Swasta AlWashliyah 24 Pasar Senen Medan yaitu topologi Star ditambah dengan management Hierarchical Token Bucket dan Peer Connection Queue (PCQ). Dimana bentuk topologi jaringan berupa konvergensi dari node tengah ke setiap node atau pengguna. Masingmasing workstation di hubungkan secara langsung ke Server atau Hub/Swich. Intinya topologi ini mengunakan Hub/Switch untuk menghubungkan dari komputer satu ke komputer yang lain. Hub/ Switch berfungsi untuk menerima sinyal-sinyal dari komputer dan meneruskan ke semua komputer yang terhubung dengan Hub/Swich tersebut.

a) Spesifikasi Device Adapun spesifikasi device yang digunakan adalah sebagai berikut :

1) Modem ADSL Huawei HG52F Wi-Fi ADSL Router dan 4-port 10/100 ethernet router berfungsi sebagai sumber internet.

2) Switch TL-SG1024

Switch seperti hub yang memiliki banyak port yang berfungsi untuk menghubungkan host atau peralatan jaringan dalam jaringan LAN. Switch dapat dikatakan device yang lebih pintar disbanding Hub, sebab selain menghubungkan komputer switch dapat mengurangi collusion domain, dan menentukan tujuan (destination) dengan cara membaca MAC address, serta memelihara daftar MAC address tersebut.

3) Router mikrotik yang digunakan berfungsi sebagai pembagi kecepatan internet (bandwidth) dengan mode PPoe Client dan rule management bandwidth dengan metode PCQ dengan menggunakan RB951Ui-2nd

\section{B. Prosedur Penelitian}

Prosedur penelitian yang dimaksud ialah, proses yang dilakukan selama penelitian hingga finalisasi 
berupa pengaturan trafik secara teoritis serta dimensioning jaringan yang ideal diterapkan pada jaringan wifi di lingkungan SMAN 20 Medan. Berikut bagan prosedur penelitian yang akan dilakukan.

Page | 30

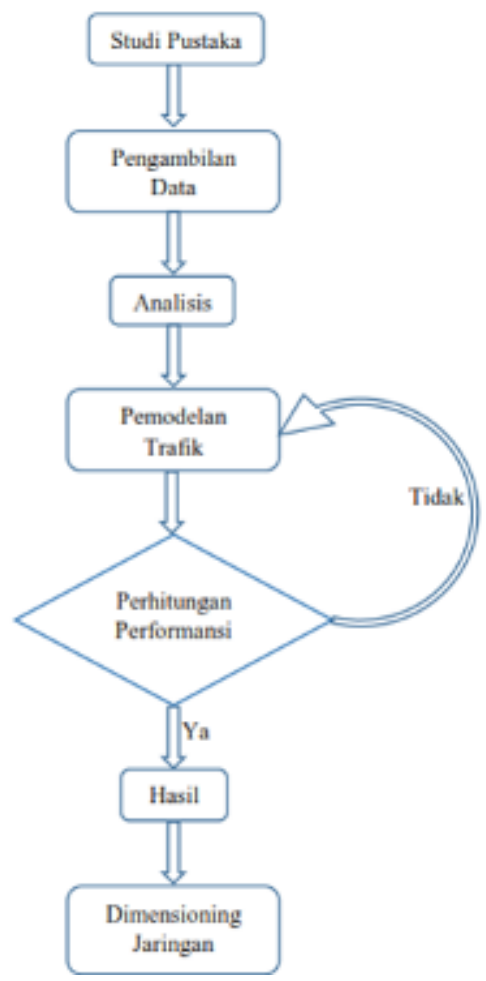

Gbr 2. Bagan prosedur penelitian

Dalam penelitian ini hal yang utama perlu diketahui adalah karakteristik dari sebuah jaringan wifi yang telah terintegerasi dengan settingan mikrotik mode PPoe client dan management bandwidth PCQ di lingkungan SMAN 20 Medan dengan melihat data trafik yang terekam.

Oleh karena itu, pengambilan data dari sebuah proses penelitian ini adalah hal yang harus dilakukan. Setelah data dan karakteristik jaringan wifi telah diketahui, dilakukan analisis dengan memodelkan persamaan yang cocok untuk performansi jaringan wifi di lingkungan SMAN 20 Medan. Hasil yang didapatkan dari pemodelan tersebut nantinya akan dijadikan dimensioning jaringan yang ideal secara toeritis atau efektif secara penggunaan dan sesuai dengan kebutuhan user.

Parameter penelitian dibutuhkan untuk membuat penelitian lebih terarah. Adapun parameter yang diamati berupa ukuran data download, delay dan loss bandwidth pada trafik sibuk dimana banyak user yang aktif pada jaringan internet SMAN 20 Medan.

Sumber data penelitian yaitu sumber subjek dari tempat mana data bisa didapatkan. Jika peneliti memakai kuisioner atau wawancara didalam pengumpulan datanya, maka sumber data itu dari responden, yakni orang yang menjawab pertanyaan peneliti, yaitu tertulis ataupun lisan. Sumber data berbentuk responden ini digunakan didalam penelitian. Dalam penelitian ini akan digunakan data kuantitatif yaitu data yang terukur. Dimana akan di uji mikrotik dengan mode PPoe menggunakan management bandwidth metode PCQ dengan ukuran parameter QoS pada trafik jaringan sibuk. Kemudian data yang digunakan data primer yaitu data yang dikumpulkan oleh peneliti sendiri atau dirinya sendiri. Ini adalah data yang belum pernah dikumpulkan sebelumnya, baik dengan cara tertentu atau pada periode waktu tertentu. Data primer dalam hal ini yaitu besarnya bandwidth, banyak user yang aktif, ukuran pembagian bandwidth per user.

Monitoring bandwidth sangatlah penting bagi staff IT untuk melihat kondisi real bandwidth yang terjadi pada trafik dengan kondisi tidak sibuk maupun kondisi sibuk. Dalam hal ini penelitian akan memanfaatkan mode modem ADSL untuk membuat bridge ke mikrotik agar mikrotik dapat di remote menggunakan jaringan eksternal SMAN 20 Medan maka mikrotik akan di setting dengan posisi PPoe client. Walaupun sudah menggunakan metode PCQ dalam pembagian bandwidth per user belum bisa mencover secara otomatis, perlu juga dipantau baik secara internal jaringan maupun di luar jaringan sewaktu-waktu mungkin saja bandwidth akan turun dikarenakan adanya trouble jaringan yang bersumber dari ISP. Kondisi ini pun harus dibutuhkan parameter yang dapat mengukur kekuatan management bandwidth pada trafik sibuk yaitu dibutuhkan analisis QoS pada management PCQ yang telah di atur.

\section{Teknik Pengumpulan Data}

Pada tahap pengumpulan data ini kegiatan yang akan dilakukan antara lain :

a. Teknik Obervasi

Pencatatan secara sistematik terhadap gejala yang nampak pada objek penelitian. Pada tahapan ini telah dilakukan oleh peneliti di lapangan dikarena kelurahan/desa Bagan Deli merupakan desa binaan fakultas ilu komputer universitas pembangunan panca budi medan. Pada tahapan ini peneliti sudah melihat objek langsung kekurang maupun kebutuhan dari objek di desa binaan tersebut.

b. Wawancara

Pengambilan data melalui wawancara /secara lisan langsung dengan sumberdatanya, baik melalui tatap muka atau lewat telephone, teleconference. Jawaban responden direkam dan dirangkum sendiri oleh tim peneliti.

c. Dokumen

Pengambilan data melalui dokumen tertulis mamupun elektronik dari lembaga/institusi. Dokumen diperlukan untuk mendukung kelengkapan data yang lain.

Populasi target pada penelitian adalah user yang aktif di kelas XI SMA N 20 Medan. Sampel yang digunakan yaitu bandwidth jaringan internet di 
SMAN 20 Medan yang termanagement dengan metode PCQ pada mikrotik dan diukur dengan ukuran data download, delay dan loss bandwidth pada trafik sibuk.

Page | 31

\section{PERANCANGAN JARINGAN}

\section{A. AlgoritMa PCQ (PER CONNECTION QUEUE)}

Algoritma $P C Q$ diawali dengan cara pengelompokkan satu substream kemudian membedakannya apabila bertambah pengguna maka akan terbentuk substream yang lainnya. Kemudian besaran antrian akan diatur oleh $P C Q$ dengan melakukan pembatasan bandwidth pada setiap pengguna. Adapun diagram algoritma dari metode PCQ dapat dilihat pada gambar 3 berikut :

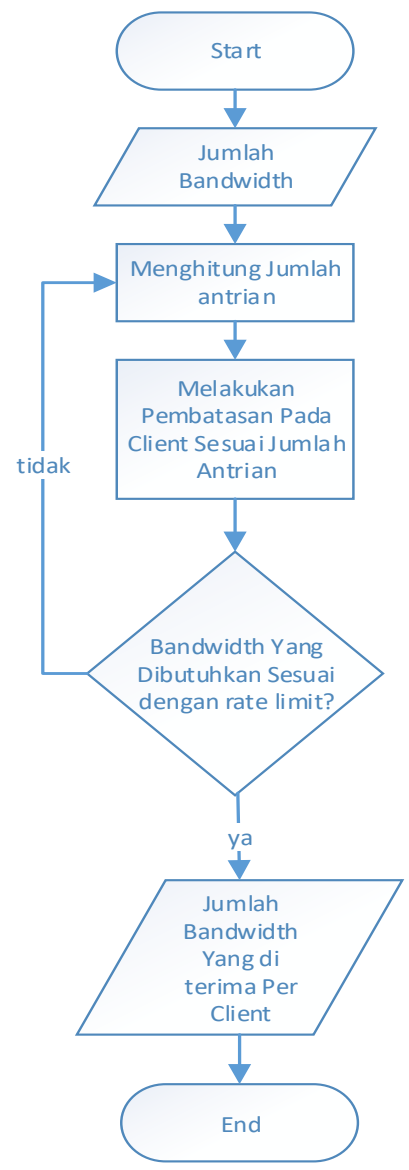

Gbr 3. Algoritma dari metode PCQ

Adapun penjelasannya dapat dilihat dari perhitungan PCQ secara manual yang diterpakan di SMAN 20 Medan berikut ini :

1) PCQ-rate $=450 \mathrm{kbps}=450000 \mathrm{bps}$ untuk 20 user di SMAN 20 Medan

Bandwidth $\mathrm{Max}=10 \mathrm{Mbps}=10 \times 1024 \mathrm{Kbps}=$ $10240 \mathrm{Kbp}$
TABEL 2. TABULASI MANAGEMENT BANDWITH PCQ-RATE LIMIT $=450 \mathrm{KBPS}$

\begin{tabular}{|c|c|c|c|c|c|}
\hline & $\begin{array}{l}2 \text { user } \\
\text { (Kbps) }\end{array}$ & $\begin{array}{l}4 \text { user } \\
\text { (Kbps) }\end{array}$ & $\begin{array}{c}10 \\
\text { user } \\
(\mathrm{Kbps})\end{array}$ & $\begin{array}{c}15 \\
\text { user } \\
(\mathrm{Kbps}) \\
\end{array}$ & $\begin{array}{c}20 \\
\text { user } \\
(\mathrm{Kbps}) \\
\end{array}$ \\
\hline \multirow{21}{*}{$\begin{array}{c}\text { Queue-pcq- } \\
\text { down-max- } \\
\text { limit=10240 } \\
\text { Kbps }\end{array}$} & 450 & 450 & 450 & 450 & 450 \\
\hline & 450 & 450 & 450 & 450 & 450 \\
\hline & & 450 & 450 & 450 & 450 \\
\hline & & 450 & 450 & 450 & 450 \\
\hline & & & 450 & 450 & 450 \\
\hline & & & 450 & 450 & 450 \\
\hline & & & 450 & 450 & 450 \\
\hline & & & 450 & 450 & 450 \\
\hline & & & 450 & 450 & 450 \\
\hline & & & 450 & 450 & 450 \\
\hline & & & & 450 & 450 \\
\hline & & & & 450 & 450 \\
\hline & & & & 450 & 450 \\
\hline & & & & 450 & 450 \\
\hline & & & & 450 & 450 \\
\hline & & & & & 450 \\
\hline & & & & & 450 \\
\hline & & & & & 450 \\
\hline & & & & & 450 \\
\hline & & & & & 450 \\
\hline & & & & & 450 \\
\hline Total & 900 & 1800 & 4500 & 6750 & 9000 \\
\hline
\end{tabular}

Dari gambar diatas dapat di lihat PCQ bekerja dengan menghitung jumlah bandwidth keseluruhan yang diberikan oleh sumber bandwidth, kemudian user yang terkoneksi akan di hitung semua, pembagian dilanjutkan secara otomatis dimana bandwidth keseluruhan yang ada akan dibagi dengan user yang aktif sehingga bandwidth di bagi secara merata. Apabila rate pada PCQ tidak di setting, maka kecepatan download pada user tidak dibatasi dan user pada saat browsing, bandwidth akan di bagi merata secara otomatis. Oleh karena itu jika user download menggunakan tools download ataupun tidak menggunakan tools seperti internet download manager maka bandwidth keseluruhan akan dipergunakan penuh user yang menggunakan tools tersebut.

\section{IMPLEMENTASI JARINGAN}

Implementasi menggunakan algoritma PCQ akan diimplementasikan dan dijelaskan sesuai dengan bandwidth yang dirancang yaitu :

A. Implementasi algoritma PCQ dengan kecepatan upload 128k dan download 450k di SMAN 20 Medan

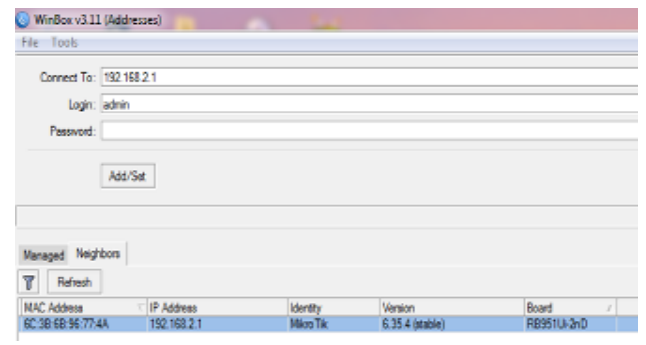

Gbr 4. Implementasi Winbox untuk login pada router mikrotik RB951 
Pada gambar di atas aplikasi winbox v3.11 berjalan pada sistem operasi windows 732 bit yang digunakan pada computer client di laboratorium SMAN 20 Medan. Aplikasi winbox ini berfungsi untuk meremote routerboard mikrotik sesuai dengan hak akses yang telah disetting pada system, user.

Page|32 Perintah yang dapat digunakan dalam bentuk tampilan GUI dan CLI, setelah di klik aplikasi winbox v3.11, kemudian tombol ... di klik untuk memilih MAC Address atau IP Address, dalam hal ini klik MAC Address didapat setelah refresh yaitu MAC Address 6C:3B:6B:96:77:4A. Adapun tampilan proses selanjutnya dapat di lihat pada gambar 4 berikut :

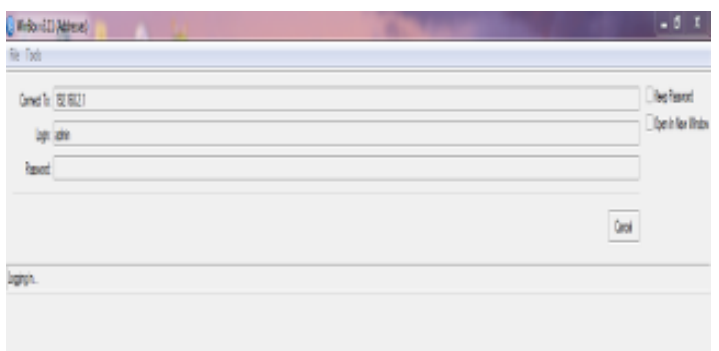

Gbr 5. proses login kedalam aplikasi Winbox RB951-UI2nd

Jika berhasil proses login pada aplikasi winbox $\mathrm{V}$ 3.11 dengan perangkat RB 951UI-2nd, maka akan muncul beberapa tampilan menu dari aplikasi winbox dengan perintah berbasis GUI dan memanfaatkan tombol klik, dapat juga menggunakan perintah CLI (Command Line Interface) maka di klik new terminal dapat di lihat pada gambar 5 berikut :

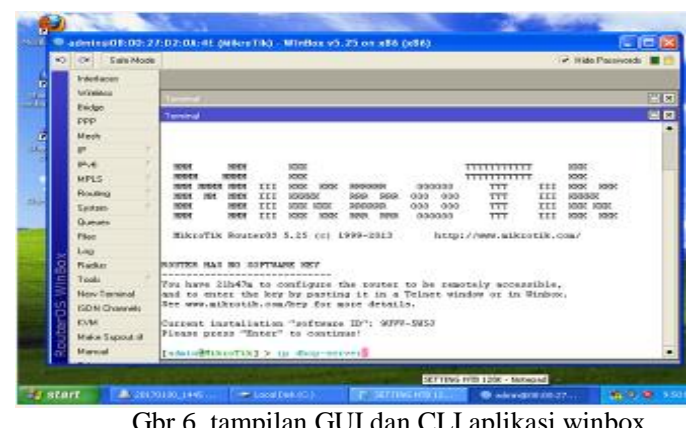

Pada client akan dilakukan penggunaan IP Address yang terbatas agar memudahkan setiap client termonitoring router dan terlimit oleh antrian Queue Tree. Pada jaringan tersebut IP Address akan di setting sesuai dengan perancangan jaringan dengan range IP 192.168.2.100 sampai dengan 192.168.2.120. Dalam hal ini jika client mencoba mengatur properties network clientnya menggunakan IP statis maka tidak akan terkoneksi jika IP Address yang diatur tidak sesuai dengan range IP Address 192.168.2.100 sampai dengan 192.168.2.120. Client akan mendapatkan IP DHCP jika mensetting Obtain automatically. Adapun daftar IP Address list firewall hanya pada jaringan internet SMA Negeri 20 Medan dapat dilihat pada gambar 6 sebagai berikut :

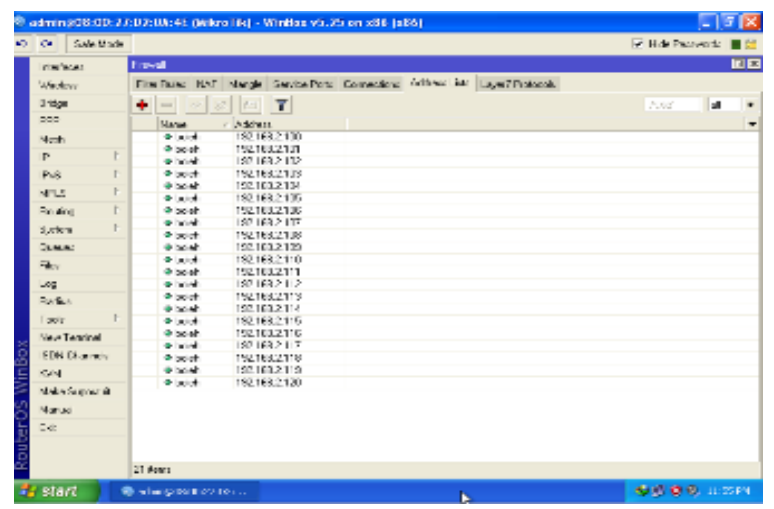

Gbr 7. tampilan IP list IP Address yang dibatasin pada aplikasi winbox

Pada tab menu adddress list di atas diketahui di buat nilai name=boleh, yaitu dizinkan untuk setiap client akan terhubung pada IP Address $=192 \cdot 168.2 \cdot 100-192 \cdot 168.2 .120$. Selain IP Adress tersebut maka tidak dapat mengakses jaringan internet di SMA Negeri 20 Medan. Dalam hal ini yang diizinkan hanya 20 user saja. Kemudian IP address yang dapat diberikan oleh router secara DHCP Server dapat dilihat pada tampilan berikut pada tab menu IP, Pool, kemudian dipilih pools untuk melihat keseluruhan IP Address yang disetting menjadi IP Addres DHCP Server yang digunakan user nantinya. Adapun tampilan dapat lihat gambar berikut :

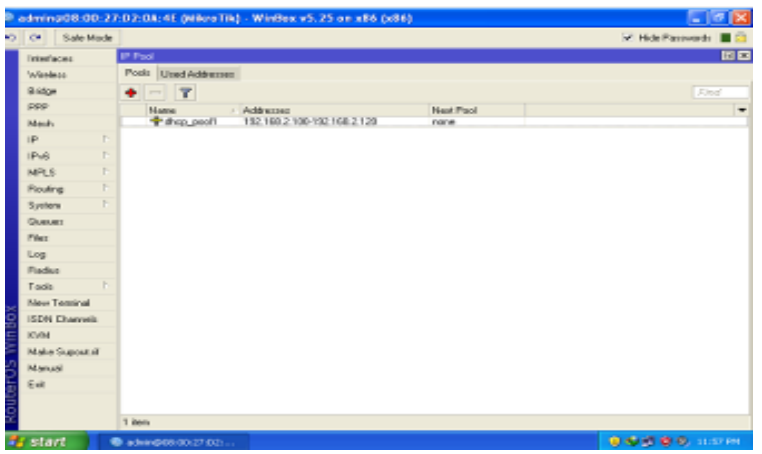

Gbr 8. Tampilan IP Address yang disetting menjadi IP Addres DHCP Server

Pada gambar di atas dijelaskan bahwa range ip address terdapat file dhcp-pool1 yaitu 192.168.2.100192.168.2.120. Kemudian dilanjutkan untuk pengujian test kecepatan bandwidth internet, dalam hal ini penulis menggunakan internet download manager dalam mengkakulasikan bandwidth maksimal yang diterima oleh user. Internet download sendiri yang digunakan sudah diregistrasi sehingga 
setiap file yang di download dibagi menjadi 8 frame file sehingga kecepatan internet yang didapat maksimal. Pada percobaan di download file berekstensi .EXE pada url website dengan address yang dapat diketikan di mozilla firefox http://www.filecroco.com/files/kits_32/install_flash_

player_ax.exe. Link tersebut untuk mendownload flash player secara offline. untuk mendownload file flash player tersebut penulis menggunakan software internet download manager versi 6.03 Beta. Karena kemampuan software ini dalam mengelolah frame file disetiap downloadnya apabila ada jaringan internet yang tidak tercover oleh suatu router maka jaringan tersebut akan down dimana user aktif bersamaan mendownload dile software init. Adapun dalam hal ini penulis mencoba untuk melihat kemampuan dari antrian Queue Tree dengan metode PCQtampilan download file dengan software download manager adalah berikut :

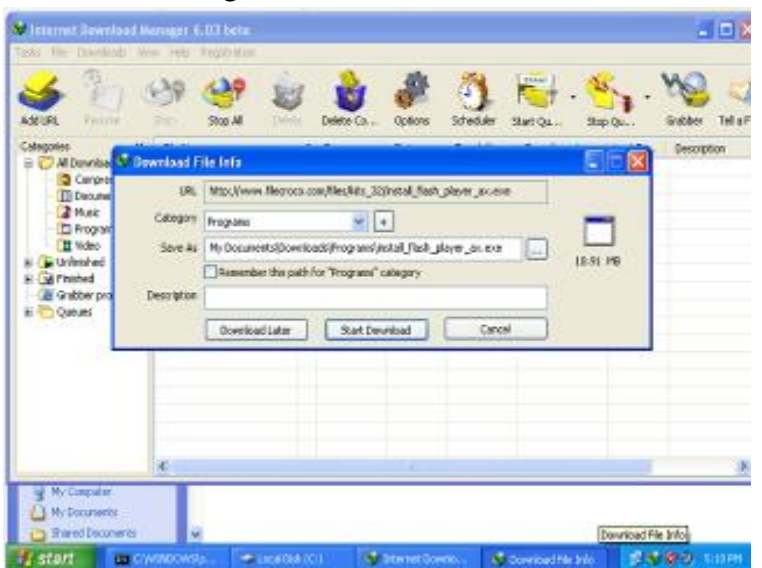

Gbr 9. Tampilan IP Address yang disetting menjadi IP Addres DHCP Server

Kemudian dapat dilihat proses download file flah player dengan ukuran 18,910 MB, jika mendapatkan bandwidth maksimum maka akan membutuhkan waktu yang cepat dalam mendownload. Sebaliknya apabila menggunakan bandwidth yang telah disetting sesuai perancangan jaringan maka bandwidth yang didapat hanya sebatas yang disetting. Adapun prosesnya dapat di lihat pada gambar 9 berikut :

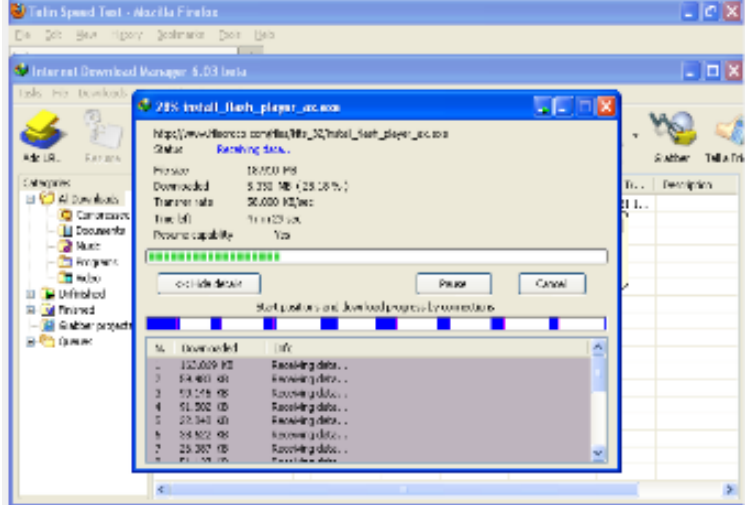

Gbr 10. Download install_flash_player_ax.exe dengan IDM $128 \mathrm{k} / 450 \mathrm{k}$

Pada gambar tersebut dapat dilihat kecepatan transfer rate yang diterima $58,00 \mathrm{~Kb} / \mathrm{sec}$ dengan time left rata rata 4 menit 29 detik.

Kemudian untuk melihat limitasi dari algoritma PCQ yang telah diterapkan dapat di lihat pada pada aplikasi winbox, klik Queue, kemudian Queue List, Queue Tree, kemudian di lihat pada upload dengan parent ether1 dengan total upload yang di limitasi sebesar 3M, dan pada download dengan parent ether2 dengan total download yang dilimitasi sebesar $10 \mathrm{M}$. Adapun tampilan Queue Tree dapat dilihat gambar di bawah ini :

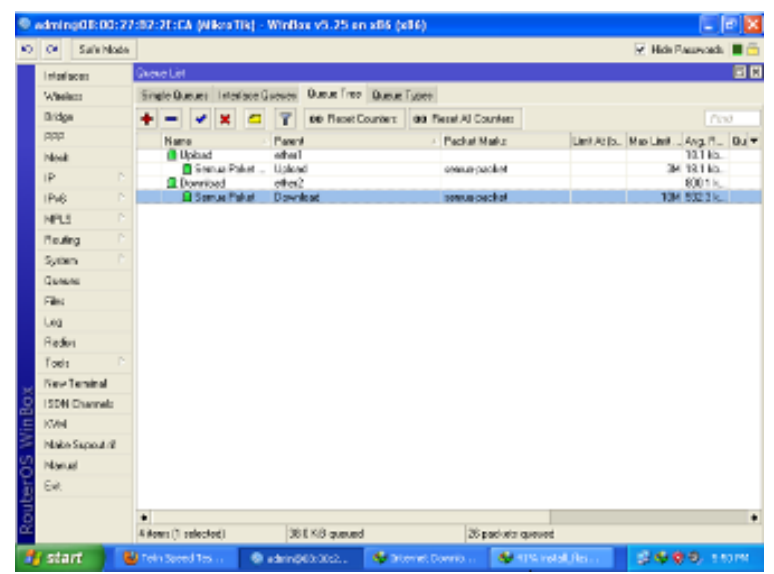

Gbr 11. Tampilan Queue Tree dengan total upload 3M dan download 10M

Pada gambar diatas diketahui adanya batasan limitasi untuk setiap total upload dan download yang sebesar nilai bandwidth yang disediakan ISP untuk pelanggannya yaitu dalam hal ini SMA Negeri 20 Medan. Untuk membatasi rate limit bandwidth download maka dibutuhkan settingan selanjutnya, adapun tampilannya sebagai berikut : 
Page | 34

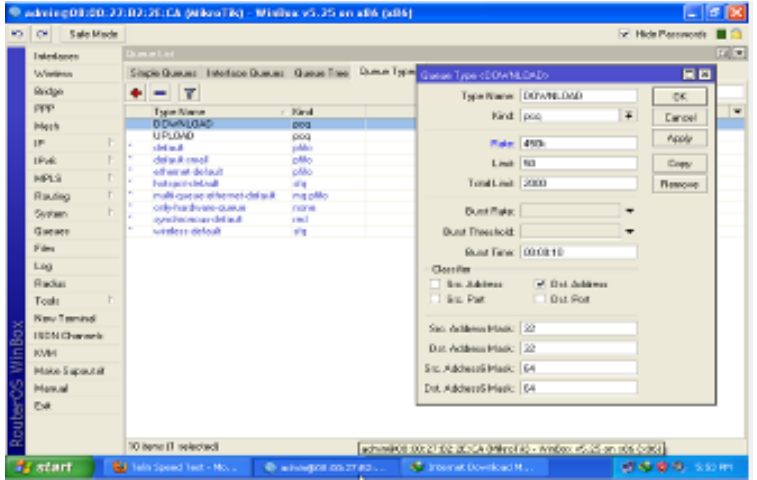

Gbr 12. Tampilan Queue Types Download dengan rate $450 \mathrm{k}$

Pada gambar diatas dapat dijelaskan bahwa pada Queue Types ditambahakan type name baru bernama DOWNLOAD dengan kind di pilih PCQ merupakan algoritma yang penulis pakai selanjutnya diatur juga rate limit bandwidth dengan rate sebesar $450 \mathrm{k}$ sesuai dengan perancangan sebelumnya, kemudian pada classifier cheklis Dst. Address untuk fungsi download. Terakhir dilakukan proses finish dengan diklik OK untuk fungsi Queue Types download telah selesai disetting. Untuk membatasi rate limit bandwidth upload maka dibutuhkan settingan selanjutnya, adapun tampilannya sebagai berikut :

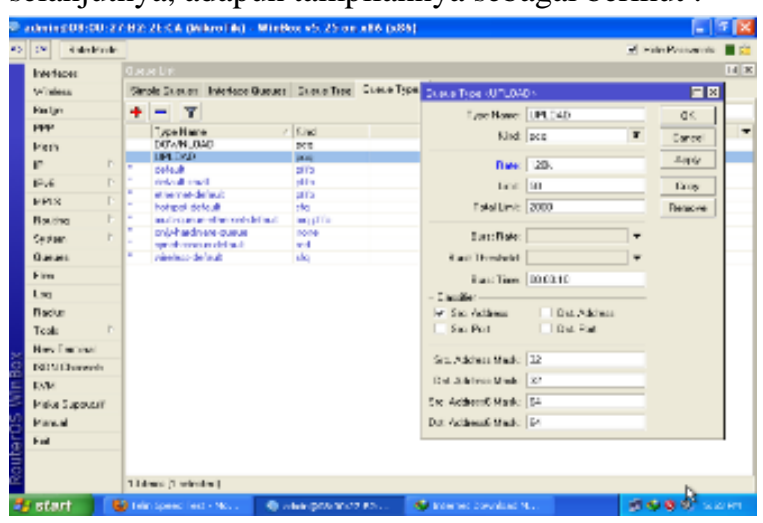

Gbr. 12 Tampilan Queue Types Upload dengan rate 128k

Pada gambar diatas dapat dijelaskan bahwa pada Queue Types ditambahakan type name baru bernama UPLOAD dengan kind di pilih PCQ merupakan algoritma yang penulis pakai selanjutnya diatur juga rate limit bandwidth dengan rate sebesar $128 \mathrm{k}$ sesuai dengan perancangan sebelumnya, kemudian pada classifier cheklis Src. Address untuk fungsi upload. Terakhir dilakukan proses finish dengan diklik OK untuk fungsi Queue Types upload telah selesai disetting.

Untuk melihat hasil settingan upload dan download yang telah disetting kemudian di atur ke queue tree, dicoba download dfile IDM pada client maka adapun tampilan di queue tree sebagai berikut:

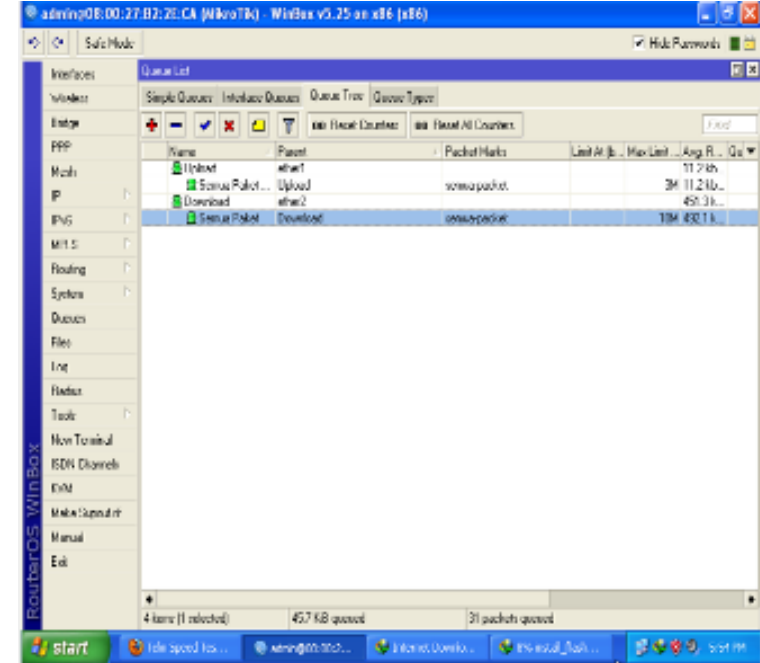

Gbr. 13 Queue Tree saat download dengan rate limit bandwidth $128 \mathrm{k} / 450 \mathrm{k}$

Pada gambar diatas diketahui jumlah avg pada upload dengan parent 1 sebesar 11,2 Kbps sesuai dengan bandwidth yang telah dirancang sebelumnya yaitu 128k untuk kecepatan upload. Jumlah avg pada download dengan parent 2 sebesar 451,2 Kbps sesuai dengan bandwidth yang telah dirancang sebelumnya yaitu 450k untuk kecepatan download. Kemudian untuk mengecek kecepatan bandwidth internet maka url yang digunakan penulis yaitu : speedtest.tellin.co.id. Adapun tampilan hasil speed test uji kecepatan internet adalah sebagai berikut :

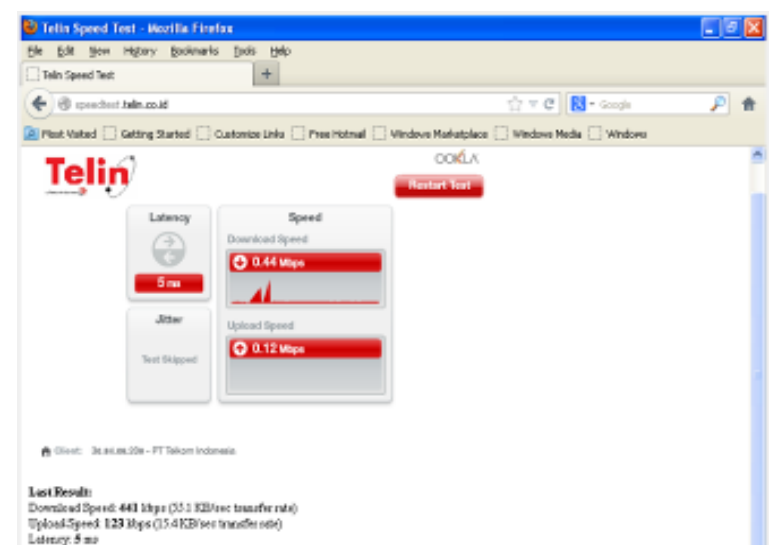

Gbr. 14 Tampilan Speedtest dengan rate limit upload 128k dan download $450 \mathrm{k}$

Pada gambar di atas didapat hasil download speed 441 kbps dengan transfer rate $55,1 \mathrm{~Kb} / \mathrm{s}$ dengan kecepatan upload sebesar $123 \mathrm{kbps}$ dengan kecepatan transfer rate $15,4 \mathrm{~Kb} / \mathrm{s}$ dan di dapat jumlah waktu yang dibutuhkan paket data untuk berpindah di seluruh koneksi jaringan (latency) sebesar $5 \mathrm{~ms}$, menurut TIPHON latency < $150 \mathrm{~ms}$ maka index koneksi internet kategory delay sangat bagus dengan indeks sebesar 4 . 


\section{B. Implementasi monitoring jaringan SMAN 20 Medan}

Untuk melihat IP Public yang kita miliki, ketikan http://www.whatismyip.com kemudian pada dialog tabel your IP Address Is catat IP Public Kita. Adapun IP Public yang digunakan pada jaringan SMA Negeri

Page | 3520 Medan yaitu sebagai berikut :

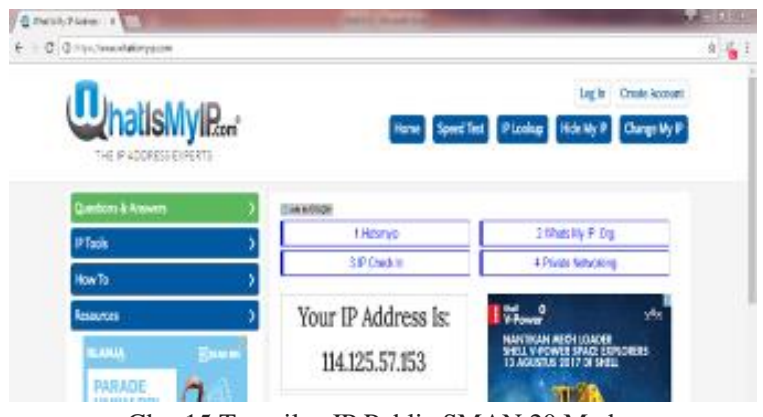

Gbr. 15 Tampilan IP Public SMAN 20 Medan

Setelah didapat IP Public SMAN 20 Medan, kemudian diinputkan IP Public tersebut diisian connect to 114.125.57.153 dengan login=admin kemudian klik connect. Adapun gambar tampilan dapat dilihat sebagai berikut:

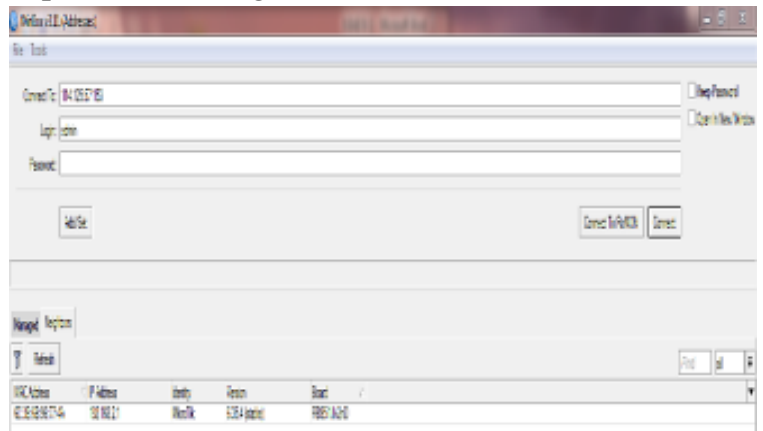

Gbr. 16 Tampilan Login Winbox dengan IP Public SMAN 20 Medan

Fungsi login winbox dengan IP Public pada gambar 33 tersebut yaitu agar routerboar mikrotik RB951-UI dapat teremote dari jaringan eksternal / di luar jaringan internet SMAN 20 Medan. Uji coba remote jaringan ini dilakukan di jaringan Lte rumah dosen dian kurnia jl. Perunggu No.14 Medan. Adapun proses login dapat di lihat pada gambar tampilan berikut :

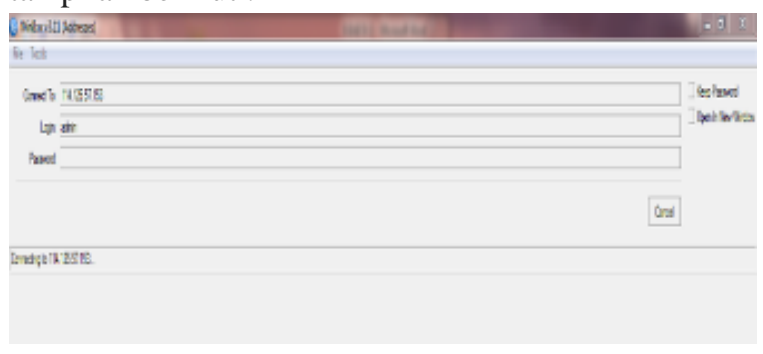

Gbr. 17 Proses Login Winbox dengan IP Public SMAN 20 Medan

\section{PENUTUP}

A. Kesimpulan

Adapun kesimpulan yang penulis perbuat adalah sebagai berikut :

a. Antrian yang digunakan untuk memanagement client di jaringan SMAN 20 Medan yaitu Queue Tree dengan algoritma PCQ yang dapat termonitoring dengan IP Public.

b. Pengujian koneksi internet pada PC-Client dilakukan dengan algoritma PCQ pada settingan upload 128k dan download 450k diketahui pengujiannya dengan menggunakan browser www.speedtest.tellin.co.id rate limit yang telah disetting tersebut berjalan sesuai dengan perancangan jaringan dan pada aplikasi internet download manager maka kecepatan download tidak melebihi batasan rate limit yang telah di setting pada queue type sebelumnya sehingga jika muncul indikator warna merah maka pada tab menu queue tree dapat di lihat akan sesuai batas rate limit yang telah ditentukan.

c. Hasil pengujian kualitas jaringan dengan paramater QoS ditemukan adanya peningkatan kualitas internet dengan adanya kinerja algoritm PCQ yaitu di dapat jumlah waktu yang dibutuhkan paket data untuk berpindah di seluruh koneksi jaringan (latency) sebesar $5 \mathrm{~ms}$, menurut TIPHON latency < $150 \mathrm{~ms}$ maka index koneksi internet kategory delay sangat bagus dengan indeks sebesar 4.

B. Saran

Adapun saran penulis untuk perkembangan penelitian ini nantinya, yaitu :

a. Penelitian dapat dikembangkan ke management bandwidth dengan antrian yang lain seperti hotspot dan HTB.

b. Menggunakan Sistem Operasi seperti linux untuk memanagement bandwidth untuk mengefesiensi biaya karena gratis lisensi.

\section{REFERENSI}

[1] Towidjojo, Rendra. 2013. Konsep \& Implementasi Routing dengan Router MIKROTIK : 200\% Connected !. Jaskom

[2] Towidjojo, Rendra. 2016. Mikrotik Kung Fu Kitab 1 Edisi Revisi. Jaskom

[3] Athailah. 2014. Panduan Singkat Menguasai Router Mikrotik untuk Pemula. Mediakita..

[4] Mirsantoso, T.U. Kalsum, R. Supardi. Implementasi Dan Analisa Per Connection Oueue (PCO) Sebagai Kontrol Penggunaan Internet Pada Laboratorium Komputer. Jurnal Media Infotama1:2. Fakultas Ilmu Komputer Universitas Dehasen Bengkulu.

[5] https://ecs7.tokopedia.net/img/ tanggal di akses 24 juli 2017

[6] http://www.mikrotik.co.id/artikel_lihat.php?id=65 tanggal diakses 24 juli 2017

[7] http://www.mikrotik.co.id/artikel_lihat.php?id=98 tanggal diakses 24 juli 2017 